\section{CS-13 REMISSION AND LOW DISEASE ACTIVITY STATE PREVENT HOSPITALIZATIONS AND EMERGENCY ROOM VISITS IN SYSTEMIC LUPUS ERYTHEMATOSUS PATIENTS}

${ }^{1}$ Cristina Reátegui-Sokolova*, ${ }^{1}$ Rocio V Gamboa-Cardenas, ${ }^{1}$ Mariela Medina-Chinchón,

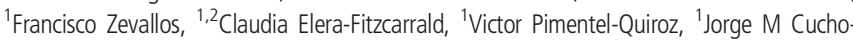
Venegas, 1,3Zoila Rodriguez-Bellido, ${ }^{1,3}$ Cesar A Pastor-Asurza, ${ }^{1,3}$ Risto Perich-Campos, ${ }^{4}$ Graciela S Alarcón, ${ }^{1,2}$ Manuel F Ugarte-Gil. ${ }^{1}$ Rheumatology Department. Hospital Guillermo Almenara Irigoyen. EsSalud; ${ }^{2}$ Universidad Cientifica del Sur; ${ }^{3}$ Universidad Nacional Mayor de San Marcos; ${ }^{4}$ School of Medicine, University of Alabama at Birmingham

\subsection{6/lupus-2018-Ism.48}

Background Although the survival rate of patients with Systemic Lupus Erythematosus (SLE) has improved over the years, patients are frequently hospitalized or evaluated in the Emergency Room; these events account for most of the direct cost of these patients' care. The objective of this study is to determine whether remission and low disease activity state (LDAS) are protective of hospitalization and Emergency Room visits in our SLE patients.

Methods All hospitalizations and Emergency Room visits of Peruvian SLE patients members of the Almenara Lupus Cohort were identified during the two-years following their baseline visit. We used the baseline data (at admission to the cohort) in order to determine which factors were associated with hospitalizations and Emergency Room visits in these SLE patients. Remission was defined as a SLEDAI- $2 \mathrm{~K}=0$, prednisone $\leq 5 \mathrm{mg} / \mathrm{d}$ and immunosuppressants on maintenance dose, LDAS was defined as not on remission an a SLEDAI- $2 \mathrm{~K} \leq 4$, prednisone $\leq 7.5 \mathrm{mg} / \mathrm{d}$ and immunosuppressants on maintenance dose; antimalarials were allowed in both groups. Univariable and multivariable Poisson regression models were used to determine the impact of being on remission or LDAS on the risk of hospitalization and Emergency Room visits, adjusting for gender, age at diagnosis, socioeconomic status, disease duration, damage, comorbidities, time of exposure to prednisone and antimalarial use.

Results Of the 314 cohort patients, 92.7\% (n=291) were female, the median age of the patients was 40.7 (32.9-51.1) years, with a disease duration of 5.5 (2.6-10.3) years. Fiftynine of the patients included were hospitalized, a total of 165 times (range 2.8 per patient). In the multivariable analysis we found that remission [RR $0.036(0.005-0.259), p=0.001]$ and LDAS [RR $0.289(0.182-0.457),<\mathrm{p}=0.001]$ at baseline decrease the risk of hospitalization in SLE patients. Similarly, remission [RR: 0.019 (95\% CI 0.107 to 0.815$), p=0.019$ ] and LDAS $[\mathrm{RR}=0.383$ (95\% CI 0.222 to 0.661$), \mathrm{p}=0.001$ ] decrease the risk of Emergency Room visits. One hundredthirty-five of the 165 hospitalizations presented a defined cause, being disease activity the most common cause of hospitalization with 73 admissions (54.1\%); within them renal disease was the leading cause, with 37 admissions (50.7\%).

Conclusions Remission and LDAS decrease the risk of hospitalizations and Emergency Room visits in SLE patients. Disease activity was the most frequent cause of hospitalization and within them renal disease. These findings have economic implications for the health care system.

Acknowledgements To all the Almenara cohort patients for generously giving their time, and to coordinators and research assistants who make this study possible.

\section{CS-14 PROLONGED ANTIMALARIAL TREATMENT IS ASSOCIATED WITH INCREASED RISK FOR ELEVATED MYOCARDIAL BIOMARKERS IN SYSTEMIC LUPUS ERYTHEMATOSUS}

${ }^{1}$ Konstantinos Tselios, 'Dafna D Gladman*, ${ }^{2}$ Paula Harvey, ${ }^{2}$ Shadi Akhtari, ${ }^{1}$ Jiandong Su, ${ }^{1}$ Murray B Urowitz. 'Centre for Prognosis Studies in Rheumatic Diseases, Toronto Lupus Clinic, University Health Network, Toronto, Ontario, Canada; ${ }^{2}$ Department of Cardiology, Women's College Hospital, University of Toronto, Toronto, Ontario, Canada

\subsection{6/lupus-2018-Ism.49}

Background Antimalarial (AM)-induced cardiomyopathy (AMIC) has been rarely reported in systemic lupus erythematosus (SLE). However, given the large number of patients

Abstract CS-14 Table 1 Comparison between BNP/cTnl abnormal and BNP/cTnl normal patients

\begin{tabular}{|c|c|c|c|}
\hline $\begin{array}{l}\text { VARIABLE } \\
\text { (At assessment) }\end{array}$ & $\begin{array}{l}\text { BNP/cTnl abnormal (no history of heart disease or PAH) } \\
(n=16)\end{array}$ & $\begin{array}{l}\text { BNP/cTnl } \\
\text { normal } \\
(n=152)\end{array}$ & $P$ \\
\hline Age (y) & $54.7 \pm 15.1$ & $47.83 \pm 12.15$ & 0.037 \\
\hline SLE duration (y) & $22.54 \pm 10.44$ & $15.45 \pm 10.05$ & 0.008 \\
\hline SLEDAI-2K & $1.88 \pm 2.47$ & $2.79 \pm 3.64$ & 0.329 \\
\hline AMS for 2 years prior & $2.52 \pm 2.96$ & $3.02 \pm 3.18$ & 0.549 \\
\hline eGFR<30 $\mathrm{ml} / \mathrm{min}$ & $0(0 \%)$ & $3(2 \%)$ & 0.571 \\
\hline Hypertension & $10(62.5 \%)$ & $54(35.5 \%)$ & 0.035 \\
\hline Diuretics treatment & $5(31.3 \%)$ & $8(5.3 \%)$ & $<0.001$ \\
\hline Systolic BP at test (mmHg) & $118.4 \pm 21.7$ & $113.5 \pm 16.9$ & 0.28 \\
\hline $\begin{array}{l}\text { Diastolic BP at test } \\
(\mathrm{mmHg})\end{array}$ & $71.9 \pm 10.1$ & $69.5 \pm 11.8$ & 0.444 \\
\hline Abnormal CPK 구 & $7(43.8 \%)$ & $24(15.8 \%)$ & 0.008 \\
\hline Cumulative years on AM & $13.66 \pm 9.14$ & $7.88 \pm 8.02$ & 0.008 \\
\hline AM duration $>5.6$ years & $14(87.5 \%)$ & $69(45.4 \%)$ & 0.001 \\
\hline Corticosteroids & $8(50 \%)$ & $70(46.1 \%)$ & 0.763 \\
\hline Mean prednisone (mg/day) & $9.4 \pm 4.2$ & $7.53 \pm 5.1$ & 0.326 \\
\hline Immunosuppressives & $10(62.5 \%)$ & $87(57.2 \%)$ & 0.685 \\
\hline
\end{tabular}

AMS adjusted mean SLEDAI-2K; eGFR: estimated glomerular filtration rate, PAH: pulmonary arterial hypertension, BP: blood pressure, CPK: creatine phosphokinase, AM: antimalarials, CQ: chloroquine, HCQ: hydroxychloroquine, ? Three abnormal measurements during the last two years 